\title{
Application of Quantile Mapping Bias Correction for Mid-Future Precipitation Projections over Vietnam
}

\author{
Long Trinh-Tuan ${ }^{1}$, Jun Matsumoto ${ }^{1,2}$, Fredolin T. Tangang ${ }^{3,4}$, Liew Juneng ${ }^{3}$, Faye Cruz ${ }^{5}$, Gemma Narisma ${ }^{5,6}$, \\ Jerasorn Santisirisomboon ${ }^{4}$, Tan Phan-Van ${ }^{7}$, Dodo Gunawan ${ }^{8}$, Edvin Aldrian ${ }^{9}$, and Thanh Ngo-Duc ${ }^{10}$ \\ ${ }^{1}$ Department of Geography, Tokyo Metropolitan University, Hachioji, Tokyo, Japan \\ ${ }^{2}$ Department of Coupled-Ocean-Atmosphere-Land Processes Research (D-COP), \\ Japan Agency for Marine Earth Science and Technology (JAMSTEC), Yokosuka, Kanagawa, Japan \\ ${ }^{3}$ Centre for Earth Sciences and Environment, Faculty of Science and Technology, Universiti Kebangsaan Malaysia, \\ Bangi, Selangor, Malaysia \\ ${ }^{4}$ Ramkhamhaeng University Center of Regional Climate Change and Renewable Energy (RU-CORE), \\ Bangkok, Thailand \\ ${ }^{5}$ Manila Observatory, Quezon City, Philippines \\ ${ }^{6}$ Atmospheric Science Program, Physics Department, Ateneo de Manila University, Quezon City, Philippines \\ ${ }^{7}$ Department of Meteorology and Climate Change, VNU University of Science, Hanoi, Vietnam \\ ${ }^{8}$ Research and Development Center, Agency for Meteorology Climatology and Geophysics (BMKG), Jakarta, Indonesia \\ ${ }^{9}$ Agency for Assessment and Application of Technology (BPPT), Jakarta, Indonesia \\ ${ }^{10}$ Department of Space and Aeronautics, University of Science and Technology of Hanoi (USTH), \\ Vietnam Academy of Science and Technology (VAST), Hanoi, Vietnam
}

\begin{abstract}
The Quantile Mapping (QM) bias correction (BC) technique was applied for the first time to address biases in the simulated precipitation over Vietnam from the Regional Climate Model (RegCM) driven by five Coupled Model Intercomparison Project Phase 5 (CMIP5) Global Climate Model (GCM) products. The QM process was implemented for the period 1986-2005, and subsequently applied to the mid-future period 2046-2065 under both Representative Concentration Pathway (RCP) 4.5 and RCP 8.5. Comparison with the original model outputs during the independent validation period shows a large bias reduction from $45 \%$ to $3 \%$ over Vietnam and significant improvements in representing precipitation indices (PI) after applying the QM technique. Moreover, the ensemble average of the $\mathrm{BC}$ products generally performed better than an individual $\mathrm{BC}$ member in capturing the spatial distribution of the PIs. A drier condition with a longer rainfall break, and shorter consecutive rainfall events are anticipated over Northern and Central Vietnam during their respective wet seasons in the mid-future. Furthermore, this study showed that the QM method minimally modified the future changes in PIs over most of Vietnam; thus, these corrected projections could be used in climate impacts and adaptation studies.
\end{abstract}

(Citation: Trinh-Tuan, L., J. Matsumoto, F. T. Tangang, L. Juneng, F. Cruz, G. Narisma, J. Santisirisomboon, T. Phan-Van, D. Gunawan, E. Aldrian, and T. Ngo-Duc, 2018: Application of quantile mapping bias correction for mid-future precipitation projections over Vietnam. SOLA, 15, 1-6, doi:10.2151/sola.2019-001.)

\section{Introduction}

Vietnam is heavily affected by climate change (MONRE 2009). Reliable information about future climate is thus important to support policy makers for climate change adaptation and mitigation in Vietnam. Since global climate models (GCMs) are not yet able to provide climate variables at fine spatial scales, regional climate models (RCMs) have been used to dynamically downscale

Corresponding author: Thanh Ngo-Duc, University of Science and Technology of Hanoi - Department of Space and Aeronautics, 18 Hoang Quoc Viet, Hanoi 10000, Viet Nam. E-mail: ngo-duc.thanh@usth.edu.vn.
GCM outputs to obtain information at a higher resolution in Vietnam (e.g. Phan et al. 2009; Ngo-Duc et al. 2014; Van Khiem et al. 2014; Katzfey et al. 2016; Raghavan et al. 2017).

Although RCMs can represent regional and even local scale climate conditions, there remain several systematic errors, especially in the mean precipitation and extreme precipitation (Giorgi et al. 1999; Ngo-Duc et al. 2017). Similar with GCMs, RCMs are also sensitive to parameterization, which leads to model biases and uncertainties (Cruz et al. 2017; Juneng et al. 2016). Examples of biases in extreme precipitation events include overestimation of drizzle days and underestimation of high precipitation values (Leander and Buishand 2007). These biases in precipitation introduce fairly large uncertainties in climate change projections, which could limit their applicability in climate impact studies. Therefore, it is necessary to apply appropriate bias correction (BC) methods to simulate extreme precipitation realistically (Christensen et al. 2008; Maraun 2013).

There are different $\mathrm{BC}$ techniques that have been put into practice; among them Quantile Mapping (QM) has been widely used (e.g. Themeß1 et al. 2012; Ngai et al. 2017). QM is used to calibrate the cumulative distribution function (CDF) of the modeled data into the CDF of the observations using a transfer function (TF). Piani et al. (2010) showed that the QM technique performed fairly well for simulated daily precipitation over Europe. Dosio et al. (2011) applied the QM technique on 11 RCMs in the Ensemble-Based Predictions of Climate Changes and their Impacts (ENSEMBLES) project (Van der Linden et al. 2009). Their study proved that the technique well represented the tails of the precipitation probability distribution functions, showing the improvement in representing extreme events. Gudmundsson et al. (2012) compared different $\mathrm{BC}$ methods and demonstrated that the QM had the best skill in reducing biases from RCM precipitation. Chen et al. (2013) assessed the hydrological impacts of BC methods and showed that distribution-based methods, including QM were consistently better than mean-based methods.

In the present study, the applicability of the QM technique is explored to bias correct the precipitation in Vietnam derived from the simulations conducted under the framework of the Coordinated Regional Climate Downscaling Experiment - Southeast Asia (CORDEX-SEA) (Tangang et al. 2018). To our knowledge, no BC method except only a simple mean bias removal has been applied so far in the previous published climate projections in 
Vietnam (Ho et al. 2011; Ngo-Duc et al. 2014; Raghavan et al. 2017). Moreover, those previous studies used scenarios based on the Intergovernmental Panel on Climate Change (IPCC) Special Report on Emissions Scenarios (SRES) (Nakicenovic et al. 2000), whereas the CORDEX-SEA simulations used the Representative Concentration Pathways (RCPs) adopted by IPCC in its Fifth Assessment Report (IPCC 2013). The performance of the QM technique is first examined before its application on the projected precipitation in the mid-future period. Furthermore, this study also examines for the first time whether the QM BC modifies the original future precipitation changes in Vietnam.

\section{Data and methodology}

\subsection{Numerical experiments}

The Regional Climate Model version 4.3 (RegCM) (Giorgi et al. 2012) with the configuration described in Juneng et al. (2016) was used to downscale the outputs of five Coupled Model Intercomparison Project Phase 5 (CMIP5) GCMs (Table 1). The RegCM output covers a common CORDEX-SEA domain of $15^{\circ} \mathrm{S}-27^{\circ} \mathrm{N}, 89.5^{\circ} \mathrm{E}-146.5^{\circ} \mathrm{E}$ at $25 \mathrm{~km}$ resolution (Fig. 1). In the present study, the two 20 -year periods selected for the analysis are: (1) the baseline period 1986-2005 and (2) the mid-future period 2046-2065 with two scenarios of RCP4.5 and RCP8.5.

\subsection{Quantile mapping bias correction}

The QM non-parametric technique (Gudmundsson et al. 2012), which has the additional advantage of not relying on any predetermined statistical distribution of the data, is used in this study. The period 1986-1995 was first used to derive TFs at each grid point for each month. Then, these TFs were applied to the period 19962005 to evaluate the results. In order to maximize the construction period of the TF as suggested by Reiter et al. (2016), TFs were later derived for the whole baseline period 1986-2005, and then applied to the mid-future 2046-2065.

\subsection{Observation-based rainfall data}

The Vietnam Gridded Precipitation (VnGP) dataset (NguyenXuan et al. 2016) was used as a reference dataset for the QM BC. The VnGP was built based on a high density surface rain gauge network, and has two resolutions of $0.1^{\circ}$ and $0.25^{\circ}$ for the period 1980-2010. In the present study, the dataset at the resolution of $0.25^{\circ}$ was used.

\subsection{Precipitation indices}

Six precipitation indices (PIs) were used, including seasonal mean precipitation (Pav), maximum consecutive dry days and wet days (CDD and CWD), simple daily intensity index (SDII), heavy precipitation days $(\mathrm{R} 20 \mathrm{~mm})$, and the $95^{\text {th }}$ percentile of daily precipitation (R95p) (Supplement ST1). The indices were estimated for each season of May to August (MJJA) and September to December (SOND). The observed and modeled PIs were first calculated on their original grid. Then, analysis was performed over the seven climatic sub-regions, including North West (R1), North East (R2), North Delta (R3), North Central (R4), South Central (R5), Central Highland (R6), and South (R7) (Fig. 1). The subregion classification was based on climate characteristics (Nguyen and Nguyen 2004), and has been widely accepted by the climate community of Vietnam (e.g. Phan et al. 2009; Ho et al. 2011). Fur-

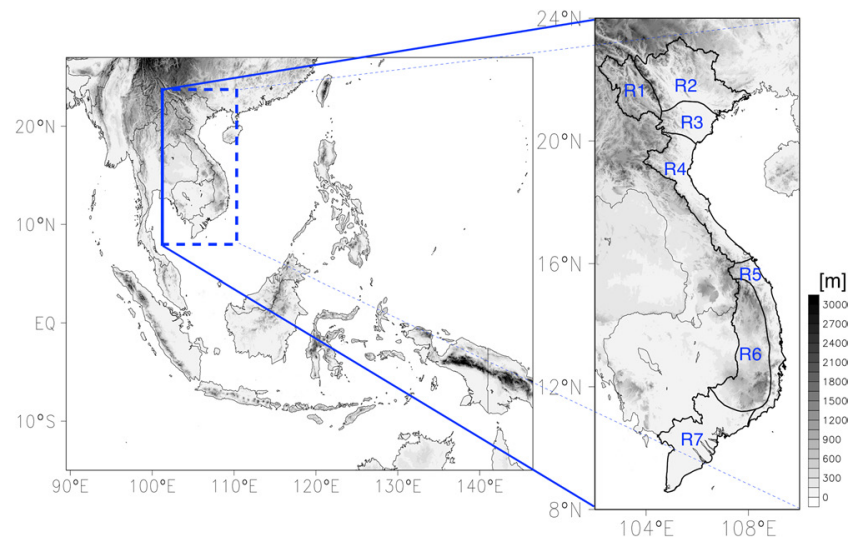

Fig. 1. CORDEX-SEA domain used in the numerical downscaling experiments, and the study region of inland Vietnam. Topography over Southeast Asia (shaded) is obtained from the Global 30 Arc-Second Elevation (GTOPO30) dataset. The seven climatic sub-regions of Vietnam (R1 to R7) are also displayed.

thermore, MJJA is the period when rainfall in Vietnam is highly influenced by the summer monsoon, while SOND is when rainfall in the central regions such as R4 and R5 is highly dominated by the winter monsoon (Matsumoto 1997; Nguyen-Le et al. 2015). Rainfall in MJJA and SOND account for $\sim 90 \%$ or above of the total annual rainfall for each sub-region (estimation based on the VnGP; Supplement ST2).

\section{Results and discussion}

\subsection{Evaluation of the $Q M B C$}

Figure 2 illustrates the biases in MJJA and SOND precipitation modeled by the RCMs with and without QM BC. During MJJA, Vietnam is influenced by the southwest summer monsoon system, and high precipitation amounts are observed in northern Vietnam, the Central Highland and southern Vietnam (Matsumoto 1997). The original RCM outputs significantly overestimate the MJJA precipitation except for CNRM and CSIRO, which underestimate precipitation over a small part of R3 and R7 (Fig. 2a). The wet bias characteristics of RegCM over mainland Indochina were already reported by Juneng et al. (2016) due to the use of the MIT Emmanuel convective scheme (Emanuel and Zivkovic-Rothman 1999). Once the scheme is activated, it becomes difficult to slow down the processes involved in the scheme, resulting in excessive rainfall (Davis et al. 2009). After the QM, a large reduction in the general bias is obtained, which is usually less than $1.5 \mathrm{~mm}$ day $^{-1}$, compared to values of up to $10.5 \mathrm{~mm} \mathrm{day}^{-1}$ in the original RCM outputs.

During SOND, most of the rainfall is induced by the northeast wind, the southward migrating convection activities, and tropical cyclone (TC) activities (Yen et al. 2011; Nguyen-Le et al. 2015). In R4 and R5, the fall rainfall amount contributed $\sim 61 \%$ and $74 \%$ of the annual rainfall, respectively (estimation based on the VnGP; Supplement ST2). All original RCM products showed a noticeable underestimation of SOND rainfall in Central Vietnam

Table 1. List of selected CMIP5 GCMs downscaled using RegCM4.3 at $25 \mathrm{~km}$ resolution from the CORDEX-SEA simulations

\begin{tabular}{ccccc}
\hline $\begin{array}{c}\text { Experiment } \\
\text { Name }\end{array}$ & GCM & GCM Development Center & $\begin{array}{c}\text { GCM Resolution } \\
\text { (degrees) }\end{array}$ & $\begin{array}{c}\text { Abbreviation used for } \\
\text { Figures and text }\end{array}$ \\
\hline Exp1 & CNRM-CM5 & Centre national de Recherches Meteorologiques, France & $1.41 \times 1.41$ & CNRM \\
Exp2 & MPI-ESM-MR & Max Planck Institute for Meteorology, Germany & $1.875 \times 1.875$ & MPI \\
Exp3 & EC-Earth & EC-Earth consortium, EU & $1.125 \times 1.125$ & ECEA \\
Exp4 & CSIRO & CSIRO, Australia & $1.875 \times 1.875$ & CSIR \\
Exp5 & GFDL-ESM2M & GFDL, USA & $2.5 \times 2.0$ & GFDL \\
\hline
\end{tabular}




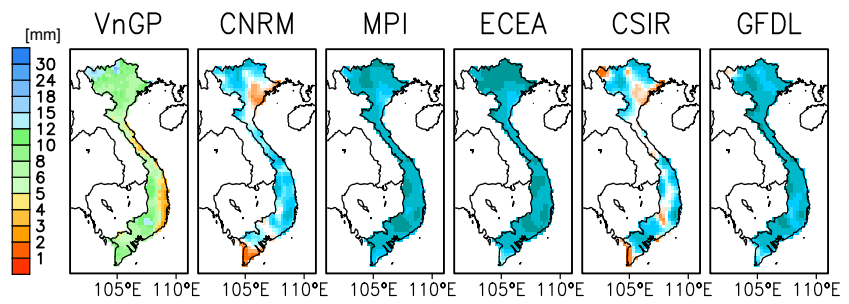

(a) MJJA
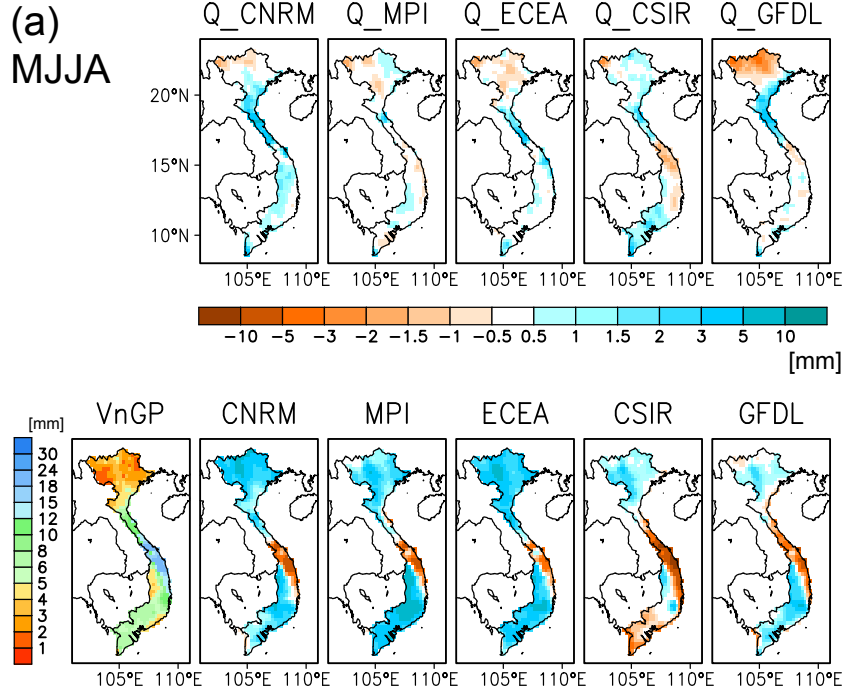

(b) SOND

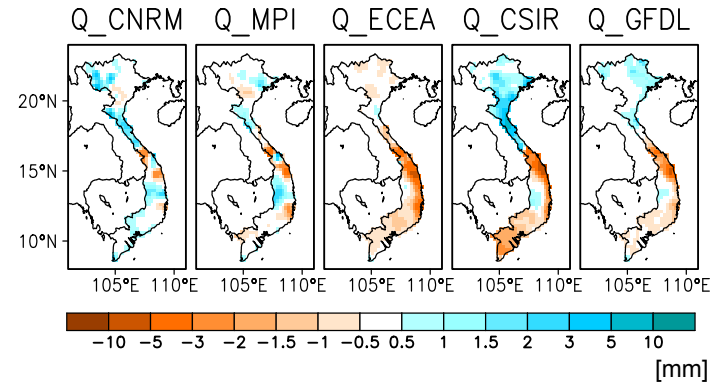

Fig. 2. Observed mean daily precipitation (VnGP) for the period 19962005, and the bias of each RCM experiment before (upper row) and after $\mathrm{BC}$ (lower row) during (a) MJJA, and (b) SOND.

(Fig. 2b). The interaction of the prevailing moisture-laden northeasterlies with the mountain ranges in the western part of Central Vietnam contributes to the abundant rainfall during this season. Thus, the underestimation of the RCM products indicates a potential deficiency in the models in representing orographic rainfall over Central Vietnam. In contrast, the models overestimated precipitation in the Northern and Southern parts of Vietnam (except for CSIRO for R7; Fig. 2b), which could be linked to the use of the convective scheme as discussed above for MJJA. The bias-corrected RCM outputs showed a remarkable improvement in bias. For the average of MJJA and SOND, the QM BC could reduce the bias from $45 \%$ to $3 \%$ over Vietnam.

In addition to the reduction in precipitation bias, the QM improved the rainfall annual cycles of the seven climatic subregions (not shown). The original and bias corrected probability density functions (PDFs) of RCM daily rainfall are also compared with that of the VnGP (Supplement SF1). The original RCM outputs tend to produce higher daily rainfall than the VnGP in all subregions, especially for rainfall thresholds less than $20 \mathrm{~mm}$ day $^{-1}$ in sub-regions R3 to R5. In addition, the variability in the original RCMs is fairly large. The corrected results reveal a significant improvement in the shape of the PDFs, wherein the PDF of the ensemble average (ENS) of the bias corrected RCM outputs is much closer and similar to that of the VnGP. It is worth noting that

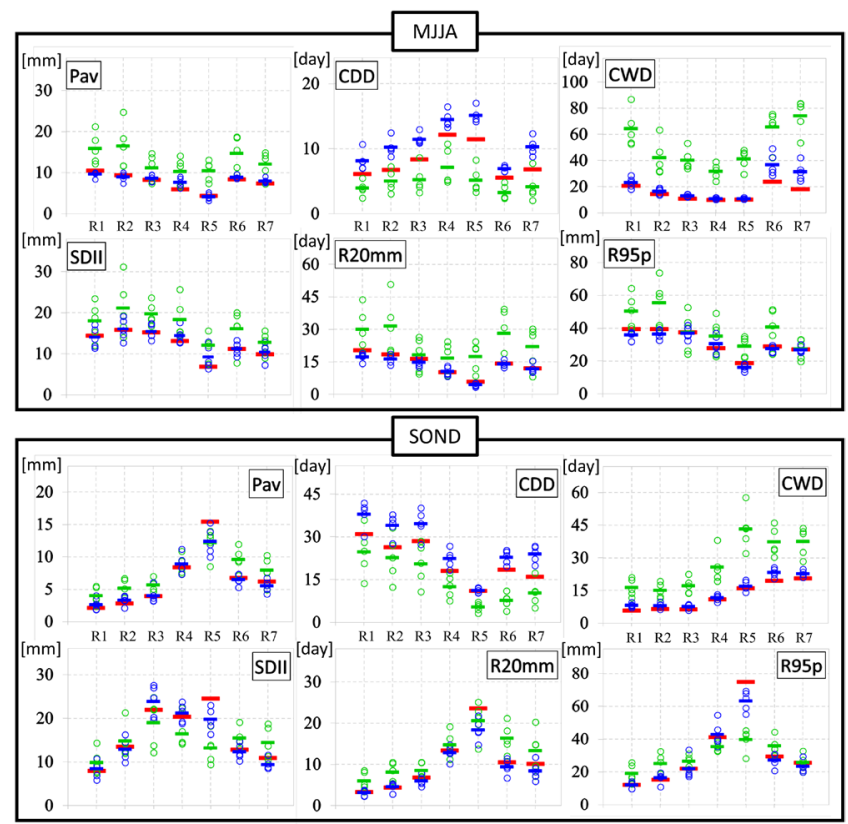

Fig. 3. Regional averages of observed and simulated PIs during 19962005. The original (uncorrected) and QM bias corrected RCMs are represented by green and blue circles, respectively, and the ensemble average values are shown by the lines. Red dashes denote the observation-based VnGP data.

the QM products generally underestimate the PDFs of low rainfall values, leading to an overestimation of CDD as shown in Fig. 3.

Figure 3 shows the regionally averaged PIs of the VnGP, and both the original and QM outputs. Due to the wet bias in RCMs, the original products tend to overestimate almost all PIs and underestimate CDD in both MJJA and SOND. However, SDII and R95p were underestimated over Central Vietnam (R4 and R5) in SOND due to the dry bias in the RCMs over this region. Figure 3 also shows that the BC PIs are less variable and closer to that of the VnGP.

To investigate the ability of the QM BC in representing the spatial distribution of the PIs, the Taylor diagram (Taylor 2001) was applied and shown in Fig. 4. Overall, in both MJJA and SOND seasons, the six PIs generated from the QM outputs are in good agreement with the PIs from VnGP. The correlations of most PI values of the original RCMs are relatively low (less than 0.7 ), indicating that the RCMs cannot capture well the spatial patterns of the PIs over Vietnam. Moreover, the standard deviation ratios (STDRs) of RCMs vary significantly. After QM BC, almost all PIs show relatively higher correlation values (approximately 0.8 to 0.9 ) with largely reduced centered root-mean square difference (RMSD). The ENS of the corrected RCM outputs exhibits higher correlations, and better STDRs and RMSDs compared to those of an individual RCM.

Although not shown in the figures, other PIs, such as maximum 1-day precipitation (Rx1day) and maximum consecutive 5-day precipitation ( $\mathrm{R} \times 5$ day), were also analyzed. However, it is worth noting that the QM BC did not improve Rx1day and Rx5day, which define the single most extreme values of a season. Since the QM technique is based on the CDFs of the VnGP and the RCM outputs, its application for the single most extreme values therefore could generate much different results from the observed.

\subsection{Projected changes in precipitation and PIs}

As shown above, the ENS performs better than any individual member in representing the observed spatial distributions of the PI values. Therefore, the five RCM experiments are considered together in a multi-model ensemble mean to provide future projections of rainfall over Vietnam.

In general, the changes under both RCP4.5 and RCP8.5 are 

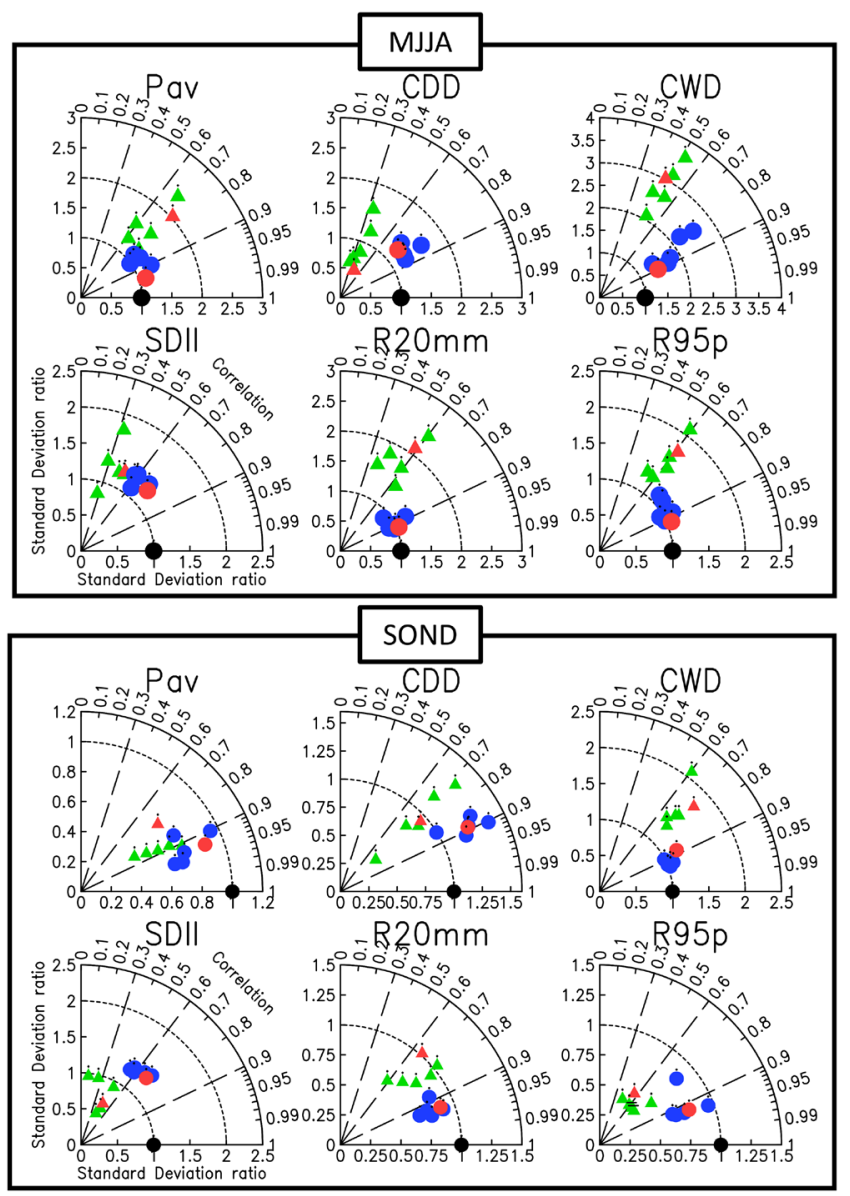

Fig. 4. Taylor diagrams for comparing the PIs of the original (uncorrected) and QM bias corrected RCM outputs with that of the VnGP (black circle). Green triangles and blue circles represent the RCM products before and after the QM BC, respectively. Red triangles and red circles indicate the ensemble average of the RCMs.

fairly similar (Fig. 5). MJJA rainfall in the North and SOND rainfall in Central Vietnam are projected to decrease under both scenarios, but more areas may experience drier conditions under RCP8.5. Ngo-Duc et al. (2014) and Raghavan et al. (2017) also found drier conditions in Northern Vietnam in their JJA projected rainfall products with the A1B SRES scenario; however no consistent trend was found for SOND rainfall in the Central region. Ho et al. (2011) and Manomaiphiboon et al. (2013) attributed the drier conditions to a negative correlation pattern between projected rainfall and sea surface temperature and a weakening of monsoonal westerly flow in JJA. Another potential factor for the decrease in projected rainfall could be linked to the possible reduction in future TCs (e.g. Yokoi et al. 2013) as TC induced rainfall can account for $\sim 25 \%$ over Central Vietnam (Nguyen-Thi et al. 2012).

As a consequence of the rainfall decrease, CDD increases over the northern and southern regions in MJJA in both scenarios with a high consistency among the models. In SOND, the increase in CDD could be observed in Central Vietnam under RCP4.5, which extends southward under RCP8.5. As for CWD, it is projected to consistently decrease in Northern Vietnam under both scenarios in both seasons, and in Central Vietnam in SOND. Thus in the future, a longer rainfall break and shorter consecutive rainfall events are expected in these areas during their respective wet season. Together with the CDD increase and the CWD decrease, future heavy rain (SDII, R20mm, and R95p) is projected to decrease, particularly over Northern Vietnam in MJJA and over Central Vietnam in SOND. Similar changes for CDD and heavy rainfall

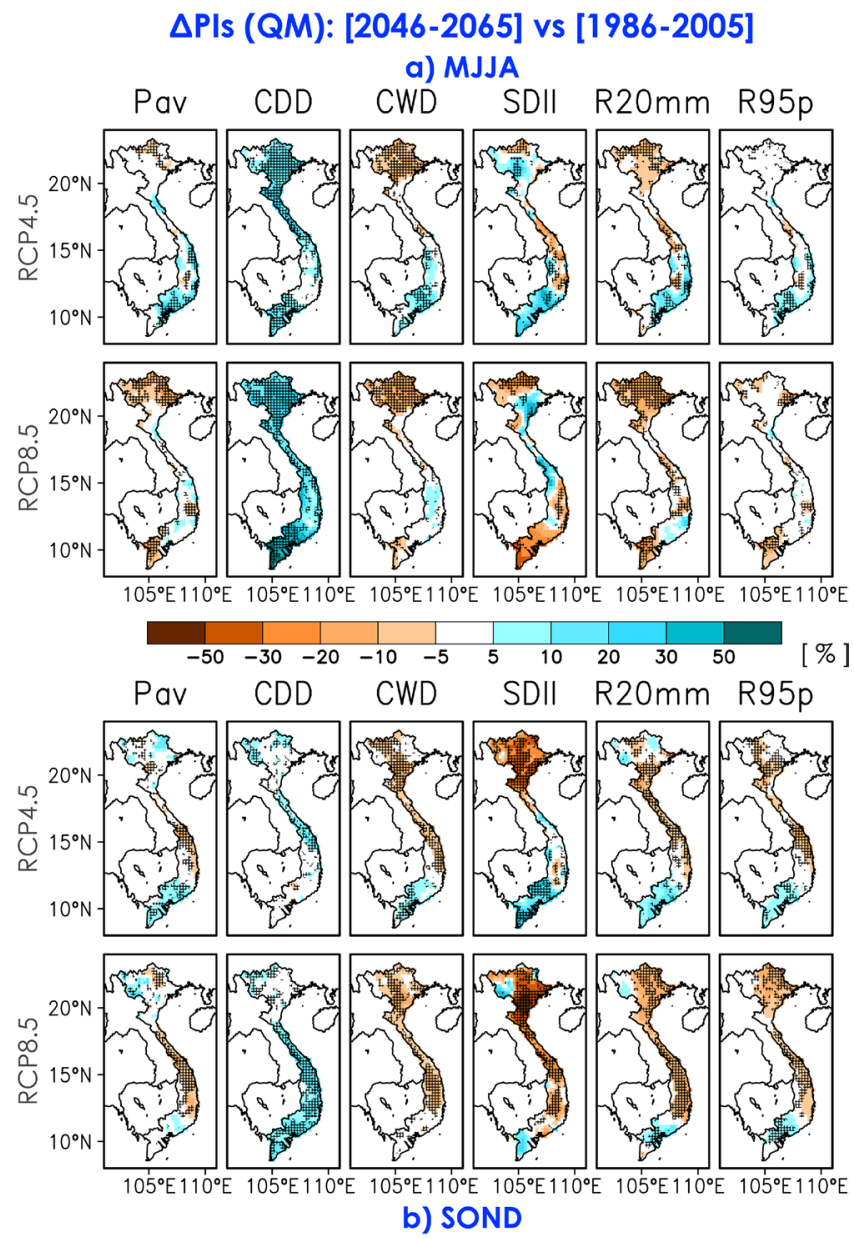

Fig. 5. Relative changes (\%) of QM BC precipitation index $(\triangle \mathrm{PIs}(\mathrm{QM}))$ between the mid-future period 2046-2065 and the baseline period 1986-2005 for (a) MJJA and (b) SOND. Hatch patterns indicate areas where at least four out of the five experiments agree in the sign of changes, i.e. where the change is called "consistent".

over Northern Vietnam were also shown in Endo et al. (2009) when they analyzed the rain-gauge data for the historical period from the 1950 s to early 2000s. In the Southern region, CWD and future heavy rain slightly increase under RCP4.5 but decrease under RCP8.5, following the changes in MJJA average rainfall. This means that depending on the regions, future rainfall can have even opposite trends under different scenarios, indicating the complex nature of rainfall variability and changes. In SOND, the changes are more robust and consistent among the experiments, wherein PIs are projected to decrease in Northern and Central Vietnam, and slightly increase in Southern Vietnam under both scenarios.

Figure 6 shows the effect of the QM BC on the future change signal compared to the original change. It can be noted that the QM method tends to slightly amplify the original projected changes, particularly in Pav, SDII, and R20 mm. Note that the sign of the change signal is almost unchanged with QM BC compared with non-BC over most of Vietnam in the wet period (i.e. SOND for Central Vietnam and MJJA for other regions). The differences between the future changes with and without $\mathrm{BC}$ are relatively small (less than 10\%), which suggests that the QM method minimally modifies the original projected changes.

\section{Conclusions}

For the first time, the QM technique was successfully applied 


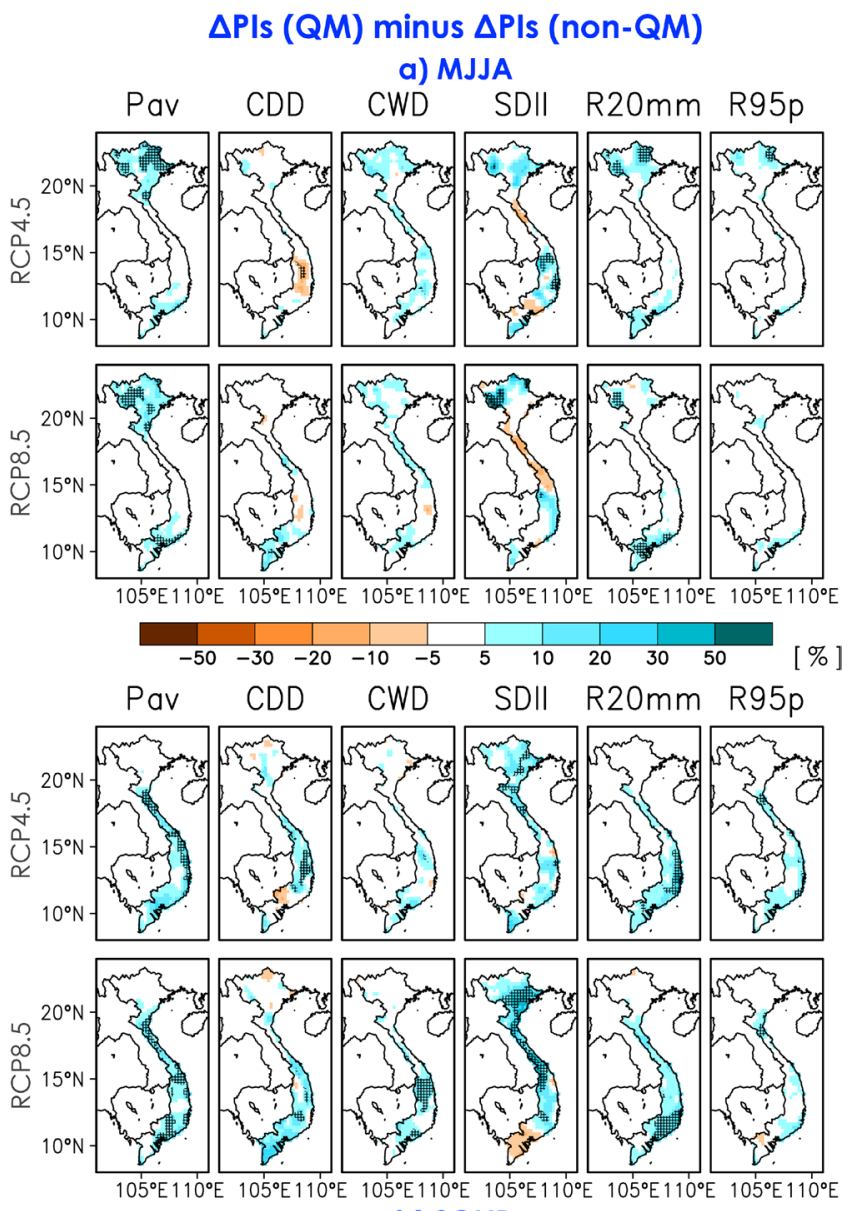

b) SOND

Fig. 6. Difference between the relative change of $\mathrm{QM} \mathrm{BC}$ precipitation index $(\triangle \mathrm{PIs}(\mathrm{QM}))$ and that of original index ( $\triangle \mathrm{PIs}($ non-QM)) for (a) MJJA and (b) SOND. Hatch patterns indicate areas where those two relative changes are opposite in sign.

to the precipitation products over Vietnam from the RCM experiments conducted under the CORDEX-SEA project. The results showed significant improvements in the QM products in representing the six PIs for both MJJA and SOND seasons in all seven sub-regions of Vietnam. Moreover, the ensemble average of the experiments performed better than any individual member in capturing the spatial distribution of the PIs.

Results also showed that the projected changes in the PIs over Vietnam in the mid-future period 2046-2065 are rather similar for both RCP4.5 and RCP8.5. In the North, drier conditions were anticipated, hence extreme rainfall amounts were projected to decrease in MJJA. Most models also indicated that Central Vietnam was projected to experience a drier wet season in SOND. In the southern region, there is a high potential for the wetter condition to persist under RCP4.5, but a drier condition may be likely under RCP8.5.

As expected, the application of the QM BC generates more realistic representation of precipitation and its extremes in the baseline period. Without $\mathrm{BC}$, a particular attention should also be given to the choice of convective parameterization to improve simulated precipitation. Another noteworthy point shown in this study is that the QM BC minimally modifies the future change signal from the original (i.e. uncorrected) projections. Thus, these QM corrected projections could be used towards a better understanding of climate change, and strengthen their applicability in further climate impact and adaptation studies.

\section{Acknowledgements}

The authors wish to thank the Editor and the two anonymous reviewers for helpful suggestions on improving the manuscript. This study is supported by the Tokyo Human Resources Fund for City Diplomacy of Tokyo Metropolitan University received from the Tokyo Metropolitan Government and by the Vietnam National Foundation for Science and Technology Development (NAFOSTED) under Grant 105.06-2018.05. CORDEX-SEA is funded by the Asia-Pacific Network for Global Change Research (APN) (ARCP2013-17NMY-Tangang/ST-2013-017, ARCP201407CMY-Tangang/ST-2015-003, ARCP2015-04CMY-Tangang/ST2015-003) and Universiti Kebangsaan Malaysia ICONIC-2013001 grant with additional support from the Department of Science and Technology Philippine Council for Industry, Energy, and Emerging Technology Research and Development (DOSTPCIEERD) of the Philippines.

Edited by: S. Ogino

\section{Supplements}

Supplemental Table 1 (ST1). Definition of the precipitation indices used in the study.

Supplemental Table 2 (ST2). Percentage contribution (\%) of MJJA and SOND rainfall to the total annual values for each subregion.

Supplemental Figure 1 (SF1). PDFs of precipitation averaged over seven sub-regions during 1996-2005. Only values larger than $1 \mathrm{~mm}$ day $^{-1}$ are shown for clarity. The light green and light blue shaded areas represent the range of values from the five models while the green and blue lines are the average of the PDFs from the original RCMs and bias-corrected RCMs, respectively. The black line is the PDF calculated from the VnGP data set.

\section{References}

Chen, J., F. P. Brissette, D. Chaumont, and M. Braun, 2013: Finding appropriate bias correction methods in downscaling precipitation for hydrologic impact studies over North America. Water Resour. Res., 49, 4187-4205, doi:10.1002/ wrcr.20331.

Christensen, J. H., F. Boberg, O. B. Christensen, and P. LucasPicher, 2008: On the need for bias correction of regional climate change projections of temperature and precipitation. Geophys. Res. Let., 35, L20709, doi:10.1029/2008GL 035694.

Cruz, F. T., and co-authors, 2017: Sensitivity of temperature to physical parameterization schemes of RegCM4 over the CORDEX-Southeast Asia region. Int. J. Climatol., 37, 5139-5153, doi:10.1002/joc.5151.

Davis, N., J. Bowden, F. Semazzi, and L. Xie, 2009: Customization of RegCM3 regional climate model for eastern Africa and a tropical Indian Ocean domain. J. Climate, 22, 35953616.

Dosio, A., and P. Paruolo, 2011: Bias correction of the ENSEMBLES high-resolution climate change projections for use by impact models: Evaluation on the present climate. J. Geophys. Res., 116, doi:10.1029/2011JD015934.

Emanuel, K. A., and M. Zivkovic-Rothman, 1999: Development and evaluation of a convection scheme for use in climate models. J. Atmos. Sci., 56, 1766-1782.

Endo, N., J. Matsumoto, and T. Lwin, 2009: Trends in precipitation extremes over Southeast Asia. SOLA, 5, 168-171, doi: 10.2151/sola.2009-043.

Giorgi, F., and C. Shields, 1999: Tests of precipitation parameterizations available in latest version of NCAR regional climate model (RegCM) over continental United States. $J$. Geophys. Res., 104, 6353-6375, doi:10.1029/98JD01164. 
Giorgi, F., and co-authors, 2012: RegCM4: model description and preliminary tests over multiple CORDEX domains. Climate Res., 52, 7-29, doi:10.3354/cr01018.

Gudmundsson, L., J. B. Bremnes, J. E. Haugen, and T. EngenSkaugen, 2012: Downscaling RCM precipitation to the station scale using statistical transformations - a comparison of methods. Hydrol. Earth System Sci., 16, 3383-3390, doi:10.5194/hessd-9-6185-2012.

Ho, T. M. H., V. T. Phan, N. Q. Le, and Q. T. Nguyen, 2011: Detection of extreme climatic events from observed data and projection with RegCM3 over Vietnam. Climate Res., 49, 87-100.

IPCC, 2013: The Physical Science Basis. Contribution of Working Group I to the Fifth Assessment Report of the Intergovernmental Panel on Climate Change, T. F. Stocker, D. Qin, G.-K. Plattner, M. Tignor, S. K. Allen, J. Boschung, A. Nauels, Y. Xia, V. Bex and P. M. Midgley, Eds., Cambridge University Press, Cambridge, United Kingdom and New York, NY, USA, $1535 \mathrm{pp}$.

Juneng, L., and co-authors, 2016: Sensitivity of Southeast Asia rainfall simulations to cumulus and air-sea flux parameterizations in RegCM4. Climate Res., 69, 59-77, doi:10.3354/ cr01386.

Katzfey, J., and co-authors, 2016: High-resolution simulations for Vietnam-methodology and evaluation of current climate. Asia-Pacific J. Atmos. Sci., 52, 91-106, doi:10.1007/s13143016-0011-2.

Leander, R., and T. A. Buishand, 2007: Resampling of regional climate model output for the simulation of extreme river flows. J. Hydrol., 332, 487-496, doi:10.1016/j.jhydrol.2006. 08.006 .

Manomaiphiboon, K., M. Octaviani, K. Torsri, and S. Towprayoon, 2013: Projected changes in means and extremes of temperature and precipitation over Thailand under three future emissions scenarios. Climate Res., 58, 97-115, doi:10.3354/ cr01188.

Maraun, D., 2013: Bias correction, quantile mapping, and downscaling: Revisiting the inflation issue. J. Climate, 26, 21372143, doi:10.1175/JCLI-D-12-00821.1.

Matsumoto, J., 1997: Seasonal transition of summer rainy season over Indochina and adjacent monsoon region. Adv. Atmos. Sci., 14, 231-245.

MONRE, 2009: Climate change, sea level rise scenarios for Vietnam. Ministry of Natural Resources and Environment, $33 \mathrm{pp}$.

Nakicenovic, N., and co-authors, 2000: IPCC Special Report on Emissions Scenarios. Cambridge University Press, Cambridge, United Kingdom and New York, NY, USA.

Ngai, S. T., F. Tangang, and L. Juneng, 2017: Bias correction of global and regional simulated daily precipitation and surface mean temperature over Southeast Asia using quantile mapping method. Global Planet. Change, 149, 79-90, doi: 10.1016/j.gloplacha.2016.12.009.

Ngo-Duc, T., C. Kieu, M. Thatcher, D. Nguyen-Le, and T. PhanVan, 2014: Climate projections for Vietnam based on regional climate models. Climate Res., 60, 199-213, doi: $10.3354 / \mathrm{cr} 01234$.

Ngo-Duc, T., and co-authors, 2017: Performance evaluation of RegCM4 in simulating extreme rainfall and temperature indices over the CORDEX-Southeast Asia region. Int. J. Climatol., 37, 1634-1647, doi:10.1002/joc.4803.

Nguyen, D. N., and T. H. Nguyen, 2004: Vietnamese Climate and Climatic Resources. Hanoi Agriculture Press, Hanoi (in
Vietnamese).

Nguyen-Le, D., J. Matsumoto, and T. Ngo-Duc, 2015: Onset of the rainy seasons in the eastern Indochina Peninsula. $J$. Climate, 28, 5645-5666, doi:10.1175/JCLI-D-14-00373.1.

Nguyen-Thi, H. A., J. Matsumoto, T. Ngo-Duc, and N. Endo, 2012: A climatological study of tropical cyclone rainfall in Vietnam. SOLA, 8, 41-44, doi:10.2151/sola.2012-011.

Nguyen-Xuan, T., T. Ngo-Duc, H. Kamimera, L. Trinh-Tuan, J. Matsumoto, T. Inoue, and T. Phan-Van, 2016: The Vietnam Gridded Precipitation (VnGP) dataset: Construction and validation. SOLA , 12, 291-296, doi:10.2151/sola.2016-057.

Piani, C., J. O. Haerter, and E. Coppola, 2010: Statistical bias correction for daily precipitation in regional climate models over Europe. Theor. Appl. Climatol., 99, 187-192, doi: 10.1007/s00704-009-0134-9.

Phan, V. T., T. Ngo-Duc, and T. M. H. Ho, 2009: Seasonal and interannual variations of surface climate elements over Vietnam. Climate Res., 40, 49-60, doi:10.3354/cr00824.

Raghavan, S. V., M. T. Vu, and S. Y. Liong, 2017: Ensemble climate projections of mean and extreme rainfall over Vietnam. Global Planet. Change, 148, 96-104, doi:10.1016/ j.gloplacha.2016.12.003.

Reiter, P., O. Gutjahr, L. Schefczyk, G. Heinemann, and M. Casper, 2016: Bias correction of ENSEMBLES precipitation data with focus on the effect of the length of the calibration period. Meteorologische Zeitschrift, 85-96, doi: $10.1127 /$ metz/2015/0714.

Tangang, F., S. Supari, J. X. Chung, F. Cruz, E. Salimun, S. T. Ngai, L. Juneng, Je. Santisirisomboon, Ja. Santisirisomboon, T. Ngo-Duc, T. Phan-Van, G. Narisma, P. Singhruck, D. Gunawan, E. Aldrian, A. Sopaheluwakan, G. Nikulin, H. Yang, A. R. C. Remedio, D. Sein, and D. Hein-Griggs, 2018: Future changes in annual precipitation extremes over Southeast Asia under global warming of $2^{\circ} \mathrm{C}$. APN Sci. Bull., 8, doi:10.30852/sb.2018.436.

Taylor, K. E., 2001: Summarizing multiple aspects of model performance in a single diagram. J. Geophys. Res., 106, 71837192, doi:10.1029/2000JD900719.

Themeß1, M. J., A. Gobiet, and G. Heinrich, 2012: Empiricalstatistical downscaling and error correction of regional climate models and its impact on the climate change signal. Climatic Change, 112, 449-468, doi:10.1007/s10584-0110224-4.

Van der Linden, P., and J. F. B. Mitchell, 2009: ENSEMBLES: Climate change and its impacts: Summary of research and results from the ENSEMBLES project. Met Office Hadley Centre Tech. Rep., 160 pp. (Available online at http:// ensemblesrt3.dmi.dk, accessed 22 September 2018)

Van Khiem, M., G. Redmond, C. McSweeney, and T. Thuc, 2014: Evaluation of dynamically downscaled ensemble climate simulations for Vietnam. Int. J. Climatol., 34, 2450-2463, doi: $10.1002 /$ joc. 3851 .

Yen, M. C., and co-authors, 2011: Interannual variation of the fall rainfall in Central Vietnam. J. Meteor. Soc. Japan, 89, 259270, doi:10.2151/jmsj.2011-A16.

Yokoi, S., Y. N. Takayabu, and H. Murakami, 2013: Attribution of projected future changes in tropical cyclone passage frequency over the Western North Pacific. J. Climate, 26, 4096-4111, doi:10.1175/JCLI-D-12-00218.1.

Manuscript received 3 October 2018, accepted 29 November 2018 SOLA: https://www.jstage.jst.go.jp/browse/sola/ 